\title{
Attitude of urban and rural would be parents towards girl child
}

\author{
RAMAN JODHA* AND ARCHANA RAJ SINGH ${ }^{1}$ \\ Department of Extension Education and Communication Management, C.C.S. Haryana Agricultural \\ University, HISAR (HARYANA) INDIA \\ ${ }^{1}$ Krishi Vigyan Kendra (S.K.R.A.U.) BIKANER (RAJASTHAN) INDIA
}

\begin{abstract}
A study was conducted in Bikaner Panchayat Samiti. For selection of samples, from each village or ward 20 male and 20 female would be parents were selected randomly. 5 male and 5 female parents and 5 male and 5 female grandparents were selected purposely to getting total sample size of 240 . The study revealed that majority of respondents had most favourable, attitude towards education, decision making, health and nutrition and mobility. In case of decision making, media exposure and mobility female respondents had most favourable attitude as compared to male respondents. Mass media exposure was positively and significantly rated with attitude of both urban and rural respondents. It also concluded from study that attitude of both urban and rural would be parents is affected from educational qualification, mass media exposure, family income, age and family type.
\end{abstract}

KEY Words : Panchayat Samiti, Respondents, Urban, Rural

View Point Article : Jodha, Raman and Singh, Archana Raj (2015). Attitude of urban and rural would be parents towards girl child. Internat. J. Home Sci. Extn. \& Comm. Manage., 2 (2): 74-78.

Article History : Received : 25.02.2015; Revised : 10.05.2015; Accepted : 11.06.2015

\footnotetext{
* Author for correspondence
} 